University of Windsor

Scholarship at UWindsor

\title{
Predicting Invasion Risk Using Measures of Introduction Effort and Environmental Niche Models
}

\author{
Leif-Matthias Herborg \\ University of Windsor \\ Christopher L. Jerde \\ University of Windsor \\ David M. Lodge \\ University of Windsor \\ Gregory M. Ruiz \\ University of Windsor \\ Hugh J. Maclsaac \\ University of Windsor
}

Follow this and additional works at: https://scholar.uwindsor.ca/biologypub

Part of the Biology Commons

\section{Recommended Citation}

Herborg, Leif-Matthias; Jerde, Christopher L.; Lodge, David M.; Ruiz, Gregory M.; and Maclsaac, Hugh J., "Predicting Invasion Risk Using Measures of Introduction Effort and Environmental Niche Models" (2007). Ecological Applications, 17, 3, 663-674.

https://scholar.uwindsor.ca/biologypub/1116

This Article is brought to you for free and open access by the Department of Biological Sciences at Scholarship at UWindsor. It has been accepted for inclusion in Biological Sciences Publications by an authorized administrator of Scholarship at UWindsor. For more information, please contact scholarship@uwindsor.ca. 


\title{
PREDICTING INVASION RISK USING MEASURES OF INTRODUCTION EFFORT AND ENVIRONMENTAL NICHE MODELS
}

\author{
Leif-Matthias Herborg, ${ }^{1,2,5}$ Christopher L. Jerde, ${ }^{3}$ David M. Lodge, ${ }^{2}$ Gregory M. Ruiz, ${ }^{4}$ \\ and Hugh J. MacIsaAC ${ }^{1}$ \\ ${ }^{1}$ Great Lakes Institute for Environmental Research, University of Windsor, Windsor, Ontario, N9B 3P4 Canada \\ ${ }^{2}$ Department of Biological Sciences, University of Notre Dame, Notre Dame, Indiana 46556 USA \\ ${ }^{3}$ Centre for Mathematical Biology, Department of Biological Sciences, University of Alberta, Edmonton, Alberta, T6G 2 E9 Canada \\ ${ }^{4}$ Smithsonian Environmental Research Center, P.O. Box 28, Edgewater, Maryland 21037 USA
}

\begin{abstract}
The Chinese mitten crab (Eriocheir sinensis) is native to east Asia, is established throughout Europe, and is introduced but geographically restricted in North America. We developed and compared two separate environmental niche models using genetic algorithm for rule set prediction (GARP) and mitten crab occurrences in Asia and Europe to predict the species' potential distribution in North America. Since mitten crabs must reproduce in water with $\geq 15 \%$ salinity, we limited the potential North American range to freshwater habitats within the highest documented dispersal distance $(1260 \mathrm{~km})$ and a more restricted dispersal limit $(354 \mathrm{~km})$ from the sea. Applying the higher dispersal distance, both models predicted the lower Great Lakes, most of the eastern seaboard, the Gulf of Mexico and southern extent of the Mississippi River watershed, and the Pacific northwest as suitable environment for mitten crabs, but environmental match for southern states (below $35^{\circ} \mathrm{N}$ ) was much lower for the European model. Use of the lower range with both models reduced the expected range, especially in the Great Lakes, Mississippi drainage, and inland areas of the Pacific Northwest. To estimate the risk of introduction of mitten crabs, the amount of reported ballast water discharge into major United States ports from regions in Asia and Europe with established mitten crab populations was used as an index of introduction effort. Relative risk of invasion was estimated based on a combination of environmental match and volume of unexchanged ballast water received (July 1999-December 2003) for major ports. The ports of Norfolk and Baltimore were most vulnerable to invasion and establishment, making Chesapeake Bay the most likely location to be invaded by mitten crabs in the United States. The next highest risk was predicted for Portland, Oregon. Interestingly, the port of Los Angeles/Long Beach, which has a large shipping volume, had a low risk of invasion. Ports such as Jacksonville, Florida, had a medium risk owing to small shipping volume but high environmental match. This study illustrates that the combination of environmental niche- and vector-based models can provide managers with more precise estimates of invasion risk than can either of these approaches alone.
\end{abstract}

Key words: ecological niche modeling; Eriocheir sinensis; genetic algorithm for rule set prediction (GARP); introduced range; invasive species; native range; relative risk; risk assessment.

\section{INTRODUCTION}

One of the most challenging problems confronting invasion biologists is the accurate identification of locations that may be successfully colonized by nonindigenous species. This requires knowledge of the number of individuals introduced into a particular area over time (i.e., propagule pressure), as well as measures of environmental suitability (where a species can survive and reproduce, i.e., its ecological niche). Only in areas where both factors are present does the risk of

Manuscript received 10 February 2006; revised 11 August 2006; accepted 25 August 2006. Corresponding Editor: J. C. Callaway.

5 Present address: Pacific Biological Station, Fisheries and Oceans, Canada, 3190 Hammond Bay Road, Nanaimo, British Columbia V9T 6N7 Canada.

E-mail: HerborgL@pac.dfo-mpo.gc.ca establishment exist. Here we combined ecological niche modeling and the release of ballast water into ports in the United States to estimate the relative risk of establishment of the invasive Chinese mitten crab. This novel approach allows for spatially focused management efforts based upon port-specific risk levels.

Ecologists have sought to link invasion success to many individual factors including diversity of native species, intensity of natural or human disturbance, resource availability, habitat productivity, and the release of invading species from natural enemies (see reviews, Lodge 1993, Levine and D'Antonio 1999, Davis and Pelsor 2001, Kolar and Lodge 2002, Levine et al. 2004, Lockwood et al. 2005, Walker et al. 2005). Recent studies have established that introduction effort (i.e., the number of introduction attempts and propagules per attempt) is positively correlated with invasion success (e.g., see Drake et al. 2005, Lockwood et al. 2005, 
Ruesink 2005, Suarez et al. 2005, Drake and Lodge 2006). Drake and Lodge (2004) applied the introduction effort concept to marine coastal environments by assessing risk based upon global shipping patterns, which were assumed to be directly proportional to the volume of ballast water discharged and the number of individuals introduced. Wonham et al. (2005) explored theoretically how different scenarios of ballast water exchange would influence introduction effort and risk associated with discharges of ballast water in coastal areas.

Many other studies have demonstrated that determinants of success may be complex, affected by multiple factors simultaneously (e.g., Lonsdale 1999, Rouget and Richardson 2003, Forsyth et al. 2004, Romanuk and Kolasa 2005). For example, Cleland et al. (2004) noted that diversity of nonindigenous plants was related to both native species diversity and resource availability, while Blumenthal (2005) proposed that release from natural enemies could account for the success of invading plant species in high-resource environments.

Stage-based approaches have also been used to predict invasion success (Colautti and MacIsaac 2004). Successful establishment of a nonindigenous species depends upon its successful navigation of a series of transitions, each with independent probabilities of failure (Carlton 1985, Kolar and Lodge 2002). A transport vector must deliver a sufficient number of viable and reproductively capable propagules to an area outside of the species' historic range. These individuals must be capable of surviving ambient physical and chemical conditions, as well as interspecific interactions with residents of the community. Movement between transitions may be influenced by one or more separate or interacting factors (Colautti et al. 2006). Furthermore, different life history attributes (e.g., growth rate, environmental tolerance) may be important for different transitions. For example, Kolar and Lodge (2002) suggested that for freshwater fish species introduced to the Laurentian Great Lakes, those with high growth rates were favored at the establishment phase but performed poorly at the spread stage.

Sequential combining of different approaches to predict invasion success may provide insights beyond the capabilities offered by individual approaches. For example, Peterson (2003) observed that areas in California that should be vulnerable to Asian longhorned beetles (Anoplophora glabripennis), based upon current inbound ship traffic from Asian source ports, are inhospitable to the beetle's environmental needs and thus unlikely to become invaded. Peterson (2003) used genetic algorithm for rule set prediction (GARP) to determine the environmental needs of the species by matching the suite of environmental conditions associated with presence of the species in its native range with the similarity of these environmental conditions in the novel range.
Genetic algorithm for rule set prediction is an environmental niche modeling application that has been used to predict range expansion and limitation for a variety of taxa including fish, reptiles, and caribou (e.g., Raxworthy et al. 2003, Johnson and Gillingham 2005, McNyset 2005). It also has been applied to studies that seek to forecast the vulnerability of sites to establishment by nonindigenous species, based upon the degree of environmental matching between the species' native and nonnative ranges (Peterson and Vieglais 2001, Ganeshaiah et al. 2003, Arriaga et al. 2004, Drake and Bossenbroek 2004, Iguchi et al. 2004, Roura-Pascual et al. 2004, Underwood et al. 2004). The approach may be particularly useful if combined with measures of introduction effort; collectively they provide managers with information on areas where species are being introduced as well as the environmental suitability of these habitats.

The focus of our study was the Chinese mitten crab (Eriocheir sinensis), a species whose native range spans from $21^{\circ}$ to $41^{\circ} \mathrm{N}$ and includes China, Hong Kong, and North Korea. The species is catadromous: its freeswimming planktonic larvae (duration $\sim 43-90$ days) develop predominantly in saline water and require salinity greater than 15 psu, although they spend much of the remainder of their life cycle in freshwater (Anger 1991). Adult crabs migrate back to estuaries, where they reproduce and die. This lifestyle constrains the range over which the species may establish viable populations to coastal rivers proximal and connected to brackish or salt water. Although the species is occasionally reported in solely freshwater habitats such as the Great Lakes (Nepszy and Leach 1973), there exists no evidence indicating that the crab can complete its entire life cycle in these habitats.

The crab initially invaded northern continental Europe between 1912 and 1940 and southern France between 1950 and 1960 (Herborg et al. 2003). It subsequently spread to Great Britain, the Spanish and Portuguese Atlantic coasts, and to Sweden, Finland, Poland, Estonia, and Lithuania proximal to the Baltic Sea (Silfverberg 1999, Valovirta and Eronen 2000, Ferdinand-Martinez and Carrera 2003). While it is inherently difficult to assess the most likely transport vector for a nonindigenous species, ballast water transport seems to be very important for mitten crabs. The initial introduction of mitten crabs into Europe occurred via ballast water (Herborg et al. 2003). Similarly, the most likely introductory pathways of mitten crabs into the United States are ballast water (Gollasch et al. 2002) or intentional introduction via the live seafood trade (Cohen and Carlton 1997).

Chinese mitten crabs have a very patchy distribution in North America, with reports of solitary individuals from Lakes Superior, Erie, and Ontario, the Detroit and St. Lawrence Rivers, the Mississippi River delta, and very recently in Chesapeake Bay (Nepszy and Leach 1973, de Lafontaine 2005; G. Ruiz, unpublished manuscript). The only locality known to support established populations 
of Chinese mitten crabs in North America is in San Francisco Bay and its watershed (Rudnick et al. 2003).

We combined the use of GARP with information on ship ballast water discharge patterns to predict the potential distribution of the Chinese mitten crab Eriocheir sinensis in North America. We developed two separate models using environmental information from the species' native range in Asia and its introduced range in Europe. We refined these predicted occurrence distributions based upon the distance of these invaded freshwater habitats to the sea in which the crab must reproduce. We used the intensity of shipping activity at major ports in the United States to identify areas most vulnerable to ballast-mediated introduction of the species. These factors were combined to determine the relative risk of invasion for each major port in the United States. Collectively, these measures provided insight into introduction effort (propagule pressure) and regions of environmental suitability, which we combined to rank the major U.S. ports in terms of risk of successful establishment of the Chinese mitten crab.

\section{Methods \\ Ecological niche modeling}

Genetic algorithm for rule set prediction is an iterative tool using an array of methods, including logit rule, range rule, negated range rule, and atomic rule, to identify heterogeneous rule sets describing a species' environmental niche. These rule sets represent different methods of identifying the environmental variables defining an ecological niche; single values of different variables (atomic rule), a statistically defined (95th percentile range) envelope for all variables (negated range rule), a range of some of the variables (range rule), and an adaptation of logistic regression (logit rules; for more details see Stockwell and Peters 1999). Models are constructed using species presence and geo-referenced environmental data. Here, we developed two separate sets of predictions for the potential distribution of the Chinese mitten crab based on its native Asian range (Asian model) and its invaded European range (European model). We selected 12 environmental variables with potential distributional importance based upon available data sets with global coverage. Variables considered included ground frost frequency, precipitation, wet day frequency, slope, aspect, topographic index, spring ocean surface temperature, river discharge, mean river temperature, and minimum, mean, and maximum air temperature (Appendix). These environmental layers were tested separately for their contributions to each model using multiple linear regressions (see Table 1), following Drake and Bossenbroek (2004). Environmental variables that contributed significantly to model prediction accuracy were then used to create 300 predictions using a 0.001 convergence limit and a maximum of 3000 iterations (per simulation), following the best subset procedure described by Anderson et al. (2003). We applied a $<5 \%$ limit on the ratio of test data points outside the predicted range (false negatives, or omission errors) and a $<50 \%$ limit for ratio of predicted suitable environments without test data points (false positives, or commission errors). Different thresholds were utilized since false negatives, representing a failure to predict actual occurrences, are a more serious problem in predicting a nonindigenous species' range than false positives, in which the species is incorrectly predicted to occur at a site and include correct predictions without presence data. The resulting 300 predictions were converted into a map of percentage of environmental match using the "Raster Calculator" in ArcMAP 9.0 (Environmental Systems Research Institute [ESRI], Redlands, California, USA). We applied hierarchical partitioning analysis of environmental layers used in the final model to identify coverages that were most important to accurate predictions. Hierarchical partitioning is based on an additional GARP prediction that uses all possible combinations of the environmental coverages used in the model and tests their effect on the overall predictive accuracy (Peterson and Cohoon 1999).

In order to distinguish between freshwater habitats in which mitten crabs can survive vs. those in which they can establish (i.e., return to the sea to reproduce), we developed a dispersal distance layer in the ecological niche model. We measured the distance between locations of reported occurrence and the nearest body of water with $\geq 15$ psu salinity using the European data set and the "Spatial Analyst" tool in ArcMAP 9.0. This dispersal distance was calculated as the shortest path downstream following the river course. Where distances were measured across large water bodies with $\leq 15$ psu salinity (Eastern Baltic Sea), the shortest possible route was taken. The maximum distance of reported occurrence was $1260 \mathrm{~km}$ from the sea ( $\geq 15 \mathrm{psu}$; Fig. 1). We also identified the 90th percentile $(354 \mathrm{~km})$ for the distribution of inland dispersal distances in Europe (Fig. 1). This limit was selected since it is not known whether crabs are established at the most distal sites for which they are reported in Europe, but they are established at the 90 th percentile distance. We applied the $1260-\mathrm{km}$ and 354-km distances as separate cut-off points for maximum expected dispersal distances for crabs in major North American rivers. The resulting layers identified waterways that are suitable for survival and are within established dispersal distance limits based upon the crab's European distribution. This procedure precluded habitats in inland states (see Figs. 2a and 3a) that otherwise conformed with GARP model predictions.

\section{Ship vector traffic to U.S. ports}

We refined our analysis further by identifying rivers that are most at risk of mitten crab establishment associated with commercial shipping, using a proxy of introduction effort. Chinese mitten crabs have been found in ballast water (Peters 1933, Gollasch et al. 2002), and we have assumed here that propagule 


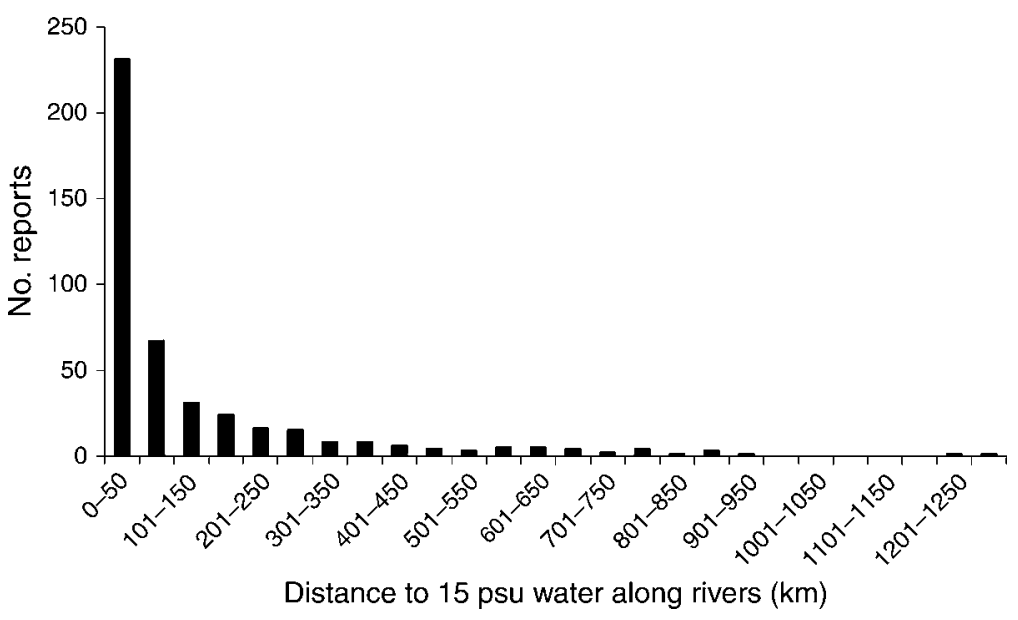

FIG. 1. Distribution of Chinese mitten crab dispersal distances in Europe. Dispersal distance is calculated as the distance from the freshwater point of occurrence to the nearest site with sufficient salinity (15 psu) for crabs to reproduce successfully. Distances were measured along rivers using ArcGIS (Environmental Systems Research Institute, Redlands, California, USA).

pressure is proportional to the volume of ballast water discharged that originated from foreign ports within the natural or introduced range of mitten crabs. We used records of ballast water discharge for the period 1 July 1999 through 31 December 2003 for ships entering the United States, which are self-reported by ships and collected and maintained by the Smithsonian Environmental Research Center (e.g., Verling et al. 2005). We considered only those ships that loaded ballast water in China or Europe and that had not exchanged ballast water while en route to U.S. destination ports. Ballast water exchange can dramatically reduce propagule pressure owing to discharge of planktonic larval (zoea, megalopa) crabs or to osmotic stress if they remain in the ships' ballast tanks (see Choi et al. 2005, Wonham et al. 2005). We also excluded vessel traffic that originated in the Mediterranean Sea as mitten crabs are not reported from this region. We assume that survival rate of ballast-borne crabs is invariant across source regions, although the actual risk posed by ships visiting from Asian ports may be reduced by the longer voyage durations and the greater mortality associated with longer trips (Verling et al. 2005).

We determined mean level of environmental suitability for major watersheds within the 354-km dispersal limit associated with U.S. ports using the "Spatial Analyst" tool in ArcMAP 9.0. This procedure allowed us to combine the total amount of ballast water received and the percentage of environmental match to develop an overall risk assessment for North American freshwater habitats.

\section{Estimating relative risk}

We defined risk of establishment as the product of propagule pressure $(P)$ and individual probability of survival $(S)$, risk $=P S$. Therefore, if propagule pressure or the probability of mitten crab survival is zero, the risk of establishment is zero at a specific port. This measure of risk can be further justified mechanistically as a binomial survival process from which the metric of risk is the expectation of the number of surviving individuals. Propagule pressure, $P$, is a measure of the number of individuals entering a location. Survival, $S$, is an individual probability. The binomial survival formulation assumes individuals act independently. Future investigations could consider the influence of nonindependent survival such that groups of individuals have different individual probabilities of survival depending on group size (Lockwood et al. 2005). Additionally, biotic factors such as competition, biodiversity, and enemy release may be incorporated into the estimates of the probability of survival (Levine et al. 2004). From the GARP analysis we were able to quantify the percentage of environmental match (GARP\%) between source (European or Asian populations of mitten crabs) and potential destination locations (U.S. ports). We assumed that the percentage of environmental match is correlated with the probability of a mitten crab surviving and eventually reproducing in the destination. From the 13 ports considered in our study, the volume of ships' ballast water was recorded for a 4.5 -year period. While this is not a direct measure of the propagule pressure, we can assume the volume $(V)$ of ballast water is proportional to the propagule pressure, $P=\alpha V$. It is crucial to note that other factors, such as inoculation frequency, may be influential on the formulation of establishment risk. While we did not include them in this study due to data limitations, future projects could consider the influence of these features and their influence on the risk formulation. Given these limitations, we reformulated risk for a port $x, \operatorname{Risk}_{x}=$ $\alpha V_{x} \times$ GARP $\%_{x}$. Because GARP $\%$ does not capture the actual probability of survival, we could not calculate the probability of establishment per se. However, if the GARP scores were similar between two locations (A and B), we could formulate a relative risk: 


$$
R=\frac{\left(\alpha V_{\mathrm{A}} \times \mathrm{GARP} \%_{\mathrm{A}}\right)}{\left(\alpha V_{\mathrm{B}} \times \mathrm{GARP} \%_{\mathrm{B}}\right)} .
$$

If the GARP\% scores were similar $\left(\right.$ GARP $\%_{A} \sim$ GARP\% $\%_{\mathrm{B}}$ ) and $\alpha$ was also assumed constant, our measure of relative risk between two locations was simply the proportion of ballast volume introduced, $\left(V_{\mathrm{A}} / V_{\mathrm{B}}\right)$. In order to allow comparisons between ports of similar environmental match, they were divided into five groups according to their GARP scores: high, 10085; medium-high, 84-50; medium-low, 49-15; low, 14-0. If the GARP scores were not similar (i.e., the ports are in different groups), then relative risk comparisons were likely not valid owing to the unknown relationship between GARP scores and survival rate.

\section{Results}

\section{Ecological niche modeling}

The GARP model developed for the native Asian range retained the following layers, each of which significantly improved model fit: precipitation (in millimeters), wet day index (number of days of precipitation), minimum, mean and maximum air temperatures (in degrees Celsius), and compound topographic index (wetness index based on flow accumulation and slope; Table 1). Hierarchical partitioning revealed that the most important contributors to model accuracy were maximum temperature, compound topographic index, minimum temperature, and precipitation level (Table 1). By contrast, the GARP model based upon the European distribution retained minimum, mean, and maximum temperature, wet day index, precipitation, topographic index, and river discharge (Table 1). Of these, temperature and wet day index were the most important contributors to model fit.

Despite differences in the importance of different environmental variables in development of Asian and European models, both sets of models yielded similar predictions of potential ranges for mitten crabs in North America (Figs. 2 and 3). The only exception to this generality was for models run without consideration of dispersal distance to the sea, i.e., models that considered only environmental and not reproductive suitability (Figs. 2A and 3A). For example, the Asian model predicted widespread environmental suitability throughout the eastern, central, and Pacific Northwest sections of the United States (Fig. 2A), whereas the European model had much lower suitability overall and particularly so for most central and western areas (Fig. 3A). The only two areas for which the European model predicted higher environmental suitability are the northern Great Lakes and along the West Coast north of Vancouver Island. Some of the areas highlighted in the Asian model (e.g., South Dakota, Nebraska) as providing suitable environmental conditions for mitten crabs are far inland from the sea and thus beyond all reported dispersal distances characteristic of the species (Fig. 1).
TABLE 1. Hierarchical partitioning of environmental variables that contributed significantly to the development of the predictive genetic algorithm for rule set prediction (GARP) models of mitten crab presence in Asia or Europe.

\begin{tabular}{lcc}
\hline \hline & \multicolumn{2}{c}{$\begin{array}{c}\text { Contribution to } \\
\text { model accuracy }(\%)\end{array}$} \\
\cline { 2 - 3 } \multicolumn{1}{c}{ Factor } & $\begin{array}{c}\text { Asian } \\
\text { GARP } \\
\text { models }\end{array}$ & $\begin{array}{c}\text { European } \\
\text { GARP } \\
\text { models }\end{array}$ \\
\hline Maximum temperature $\left({ }^{\circ} \mathrm{C}\right)$ & 34 & 15 \\
Mean temperature $\left({ }^{\circ} \mathrm{C}\right)$ & 4 & 22 \\
Minimum temperature $\left({ }^{\circ} \mathrm{C}\right)$ & 10 & 33 \\
Wet day index (no. days of precipitation) & 8 & 16 \\
Topographic index $($ wetness index based & & \\
on flow accumulation and slope) & 27 & 1 \\
Precipitation $(\mathrm{mm} / \mathrm{d})$ & 9 & 7 \\
River discharge $\left(\mathrm{km}{ }^{3} / \mathrm{yr}\right)$ & $\cdots$ & 3 \\
\hline
\end{tabular}

Note: Importance of each retained environmental variable is given as the relative percentage contribution to model accuracy.

Asian and European models that considered dispersal distance to the sea typically had a high degree of similarity in predicted range of mitten crabs. The Asian model with broad dispersal $(1260 \mathrm{~km})$ had a reduced distribution relative to the unrestricted dispersal Asian model (Fig. 2B), particularly in central parts of the continent. The crab's expected distribution with the $1260-\mathrm{km}$ dispersal limitation was restricted to the eastern seaboard from southern Nova Scotia to central Florida, in the Gulf of Mexico from central Florida to Corpus Christi, Texas, and in the Pacific Northwest from San Francisco Bay to southwestern British Columbia. Inland distribution along the eastern seaboard was constrained by the Appalachian mountains (Fig. 2A).

The European model with broad dispersal $(1260 \mathrm{~km})$ resembled that of its Asian counterpart, although environmental matching was typically lower and particularly so in the southern United States (Figs. 2B and 3B). The lower Great Lakes and upper St. Lawrence River were predicted as environmentally suitable by both Asian and European models with broad dispersal distance. In the Pacific Northwest, highly suitable environments were generally farther north into British Columbia (including Vancouver Island) in the European model, whereas the Asian model predicted greater inland penetration in Washington, Oregon, and California.

With the more stringent dispersal limit of $354 \mathrm{~km}$, consistent with the 90th percentile of observations of mitten crabs in Europe (Fig. 1), the predicted occurrence of mitten crabs with the Asian model decreased in three areas: the lower Great Lakes and upper St. Lawrence River, central sections of the Mississippi watershed, and interior areas of Washington, Idaho, northeastern California, and northwestern Nevada (Fig. 2C). Similarly, European models with constrained dispersal (Fig. $3 \mathrm{~B}, \mathrm{C})$ had the same range restrictions relative to the broad dispersal models as was noted above for the Asian models (Fig. 2B, C). 

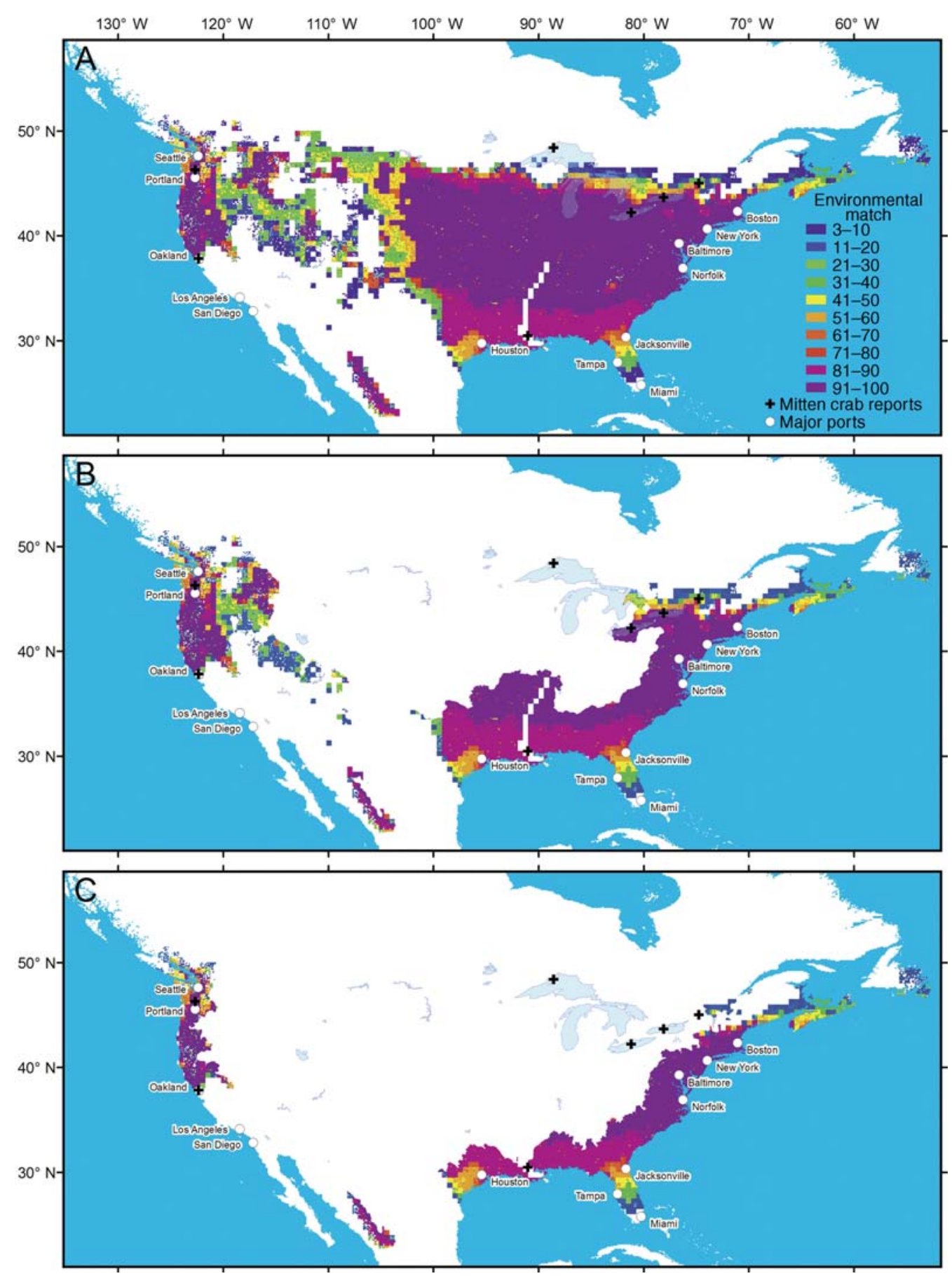

FIG. 2. Predicted occurrence of Chinese mitten crabs in North America based on the ecological niche models developed using environmental data for Asian sites of crab presence. Included in the models are (A) no dispersal limitation or (B) limitation based upon maximum $(1260 \mathrm{~km})$ or $(\mathrm{C}) 90$ th percentile $(354 \mathrm{~km})$ of reported crab dispersal distance in Europe (see Fig. 3). Dispersal distances are measured from the inland location to the nearest site with salinity $\geq 15 \mathrm{psu}$. Stars indicate occurrence reports of mitten crabs in North America; the only North American site known to have an established population is San Francisco Bay. Labels indicate U.S. ports for which ballast water discharge data were obtained to estimate introduction effort.

\section{Relative risk to U.S. ports}

The volume of non-exchanged ballast water that originated at sites in Europe or China and was discharged into the United States varies considerably among ports (Table 2) and years (not shown). Not surprisingly, ports along the eastern seaboard receive non-exchanged ballast water mainly from European donor ports, whereas those in the west receive it mainly 

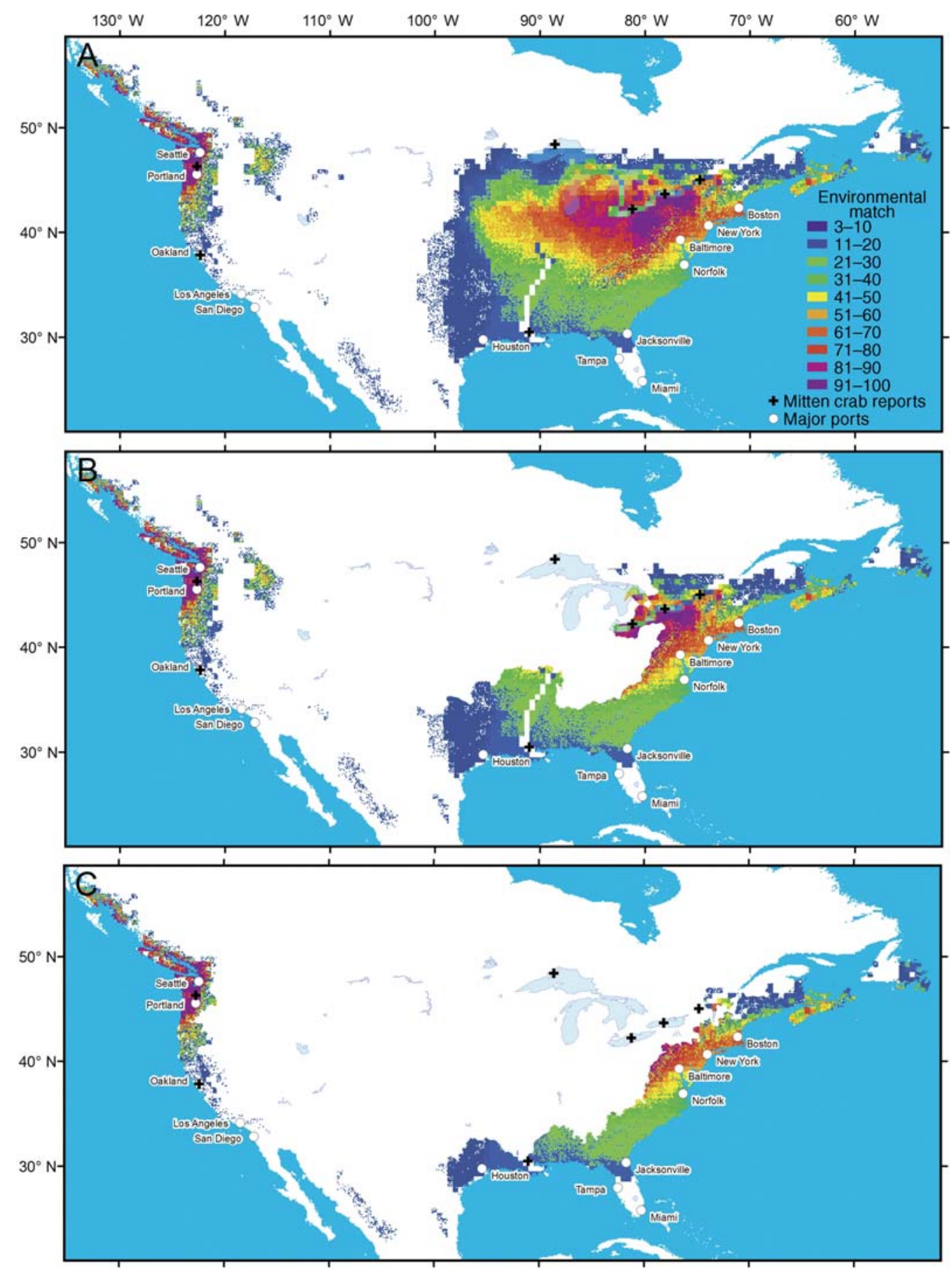

FIG. 3. Predicted occurrence of Chinese mitten crabs in North America based upon the ecological niche models developed using environmental data for European sites of crab presence. Included in the models are (A) no dispersal limitation or (B) limitation based upon maximum $(1260 \mathrm{~km})$ or $(\mathrm{C}) 90$ th percentile $(354 \mathrm{~km})$ of reported crab dispersal distance in Europe.

from China. The port of Norfolk, Virgninia, received more unexchanged ballast water from sites inhabited by mitten crabs than all of the other major ports in the contiguous United States combined (Table 2).

The ports of Norfolk and Baltimore were most vulnerable to introduction and establishment of Chinese mitten crabs. These areas were the only ports in the highrisk group in the Asian model and were also associated with the highest relative risk in the European model (Tables 2 and 3). These areas were at risk because they receive a high volume of ballast water from risky sources (i.e., propagule pressure) and had high environmental 
TABLE 2. Relative risk of invasion of the major ports in the United States based on environmental matching levels estimated by the Asian model (based on the native Asian distribution).

\begin{tabular}{|c|c|c|c|c|}
\hline \multirow[b]{2}{*}{ Group and port } & \multicolumn{2}{|c|}{ Asian model } & \multirow{2}{*}{$\begin{array}{c}\text { Ballast } \\
\text { volume (Mg) }\end{array}$} & \multirow[b]{2}{*}{ Relative risk } \\
\hline & Mean & SD & & \\
\hline \multicolumn{5}{|l|}{ High } \\
\hline Norfolk, Virginia & 98 & 8 & 365427 & 4.8 \\
\hline Baltimore, Maryland & 98 & 8 & 76160 & 1 \\
\hline \multicolumn{5}{|l|}{ Medium/high } \\
\hline Portland, Oregon & 67 & 34 & 65465 & 160.6 \\
\hline Houston, Texas & 80 & 12 & 24836 & 60.9 \\
\hline New York, New York & 84 & 31 & 21019 & 51.6 \\
\hline Seattle, Washington & 68 & 37 & 13266 & 32.6 \\
\hline Tampa, Florida & 59 & 19 & 1021 & 2.5 \\
\hline Jacksonville, Florida & 75 & 19 & 408 & 1 \\
\hline \multicolumn{5}{|l|}{ Medium/low } \\
\hline San Francisco-Oakland, California & 33 & 44 & 21718 & 5.7 \\
\hline Boston, Massachusetts & 49 & 44 & 3792 & 1 \\
\hline \multicolumn{5}{|l|}{ Low } \\
\hline Los Angeles-Long Beach, California & 0 & 0 & 30458 & 21.7 \\
\hline Miami, Florida & 13 & 13 & 1402 & 1 \\
\hline \multicolumn{5}{|l|}{ NA } \\
\hline San Diego, California & 0 & 0 & 0 & $\cdots$ \\
\hline
\end{tabular}

suitability. The relative risk of Norfolk becoming invaded was 4.8 times higher than that of Baltimore. The port of Portland had the third highest risk of invasion; it had the highest relative risk within the medium-high environmental match group in the Asian model, and the third highest in the European model. While a direct comparison of the relative risk between Portland and Norfolk and Baltimore was not possible for the Asian model (except that it is higher for the latter two), the risk was only slightly lower for Portland (4.9) than Baltimore (5.7) in the European model. However, it is also important to note that the ports of Baltimore and Norfolk occur within Chesapeake Bay and are $\sim 280 \mathrm{~km}$ apart. Other ports such as New York and Seattle had a lower risk of establishment as they had

TABLE 3. Relative risk of invasion of the major ports in the United States based on habitatmatching levels estimated by the European model (based on the invaded European distribution).

\begin{tabular}{|c|c|c|c|c|}
\hline \multirow[b]{2}{*}{ Group and port } & \multicolumn{2}{|c|}{ European model } & \multirow{2}{*}{$\begin{array}{c}\text { Ballast } \\
\text { volume }(\mathrm{Mg})\end{array}$} & \multirow[b]{2}{*}{ Relative risk } \\
\hline & Mean & $\mathrm{SD}$ & & \\
\hline \multicolumn{5}{|l|}{ Medium-high } \\
\hline Norfolk, Virginia & 53 & 17 & 365427 & 27.5 \\
\hline Baltimore, Maryland & 69 & 16 & 76160 & 5.7 \\
\hline Portland, Oregon & 63 & 36 & 65465 & 4.9 \\
\hline New York, New York & 51 & 18 & 21019 & 1.6 \\
\hline Seattle, Washington & 74 & 31 & 13266 & 1 \\
\hline \multicolumn{5}{|l|}{ Medium-low } \\
\hline Boston, Massachusetts & 25 & 21 & 3792 & 9.3 \\
\hline Tampa, Florida & 15 & 9 & 1021 & 2.5 \\
\hline Jacksonville, Florida & 21 & 7 & 408 & 1 \\
\hline \multicolumn{5}{|l|}{ Low } \\
\hline Los Angeles-Long Beach, California & 0 & 1 & 30458 & 21.7 \\
\hline Houston, Texas & 9 & 5 & 24836 & 17.7 \\
\hline San Francisco-Oakland, California & 2 & 3 & 21718 & 15.5 \\
\hline Miami, Florida & 0 & 2 & 1402 & 1 \\
\hline \multicolumn{5}{|l|}{ NA } \\
\hline San Diego, California & 0 & 0 & 0 & $\cdots$ \\
\hline
\end{tabular}

Notes: Environmental match mean scores estimated the degree of environmental compatibility (range $0-100 \%$ ) for that port's watershed (to a distance of $354 \mathrm{~km}$ upstream of the port) based upon 300 simulations. The risk proportionality was based on the ratio of ballast water received and only applies within a group of ports of similar environmental match. 
moderate ballast discharge volumes and medium-high or medium-low environmental matches (Tables 2 and 3). Other ports were expected to have a much lower risk of mitten crab establishment, either because low discharge volumes limit propagule pressure and/or because inhospitable conditions limit survival of introduced individuals. For example, risk of establishment in the Asian model for the ports of Los Angeles-Long Beach and Miami appeared to be very low owing to an inhospitable environment, despite the fact that these areas received moderate volumes of unexchanged ballast water from invaded source ports. A few ports, including Tampa and Jacksonville, were vulnerable to establishment of mitten crabs based upon environmental matching. However, as they received little unexchanged ballast water from invaded source regions, their relative risk was very low (Tables 2 and 3). The risk level for San FranciscoOakland harbor was in the medium-low category for the Asian model and low in the European model (Tables 2 and 3).

\section{Discussion}

\section{Combining environmental matching and vector transport}

The relative risk assessment presented here allows a focused management program at the most effective point of the invasion process, the pre-establishment phase (Ricciardi and Atkinson 2004, Jeschke and Strayer 2005). Our approach combined reported quantities of ballast water discharge (as a proxy for propagule pressure) with environmental matching to establish relative invasion risk for different U.S. ports. Norfolk, Baltimore, and Portland have the greatest relative risk of introduction and establishment of Chinese mitten crabs since they receive the greatest volumes of ballast water from source regions known to support the species and have the highest environmental match for both models (Tables 2 and 3). Additionally, the ports of Norfolk and Baltimore are both located in Chesapeake Bay, further increasing the overall risk for this area.

Many studies have demonstrated that survival of nonindigenous species depends on the degree of environmental similarity between donor and recipient regions, thereby implicating the importance of physiological tolerance to conditions in the introduced environment (e.g., Wonham et al. 2000, Kolar and Lodge 2002, Rouget and Richardson 2003, Forsyth et al. 2004). Genetic algorithm for rule set prediction modeling can accurately predict the occurrence of mitten crabs. The same Asian model used here was validated using the European distribution (L. M. Herborg, unpublished manuscript). Eighty-four percent of reports in Europe occurred in areas predicted as suitable by $>80 \%$ of Asian GARP models and only $4 \%$ occurred in areas predicted suitable by $<50 \%$ of Asian models. However, predicting future ranges of nonindigenous species using only environmental niche models may provide misleading forecasts since many areas suitable for colonization may lack appropriate vectors to transmit the species to these locations. Our results highlight the advantage of combining environmental matching, measures of propagule pressure, and limitations imposed by the species' catadromous life cycle for estimating establishment risk. For example, central portions of the United States outside of the maximum known dispersal capability of mitten crabs were nevertheless predicted as environmentally suitable (e.g., Figs. 2A and 3A) for the species. Similarly, the combined port system of Los AngelesLong Beach received relatively high volumes of ballast discharge from key source regions (Table 2) and has considerable risk to establishment of Chinese mitten crabs based solely on propagule supply. However, when combined with information on environmental matching, our analysis indicated that this port system had a low risk of invasion (Tables 2 and 3). Jacksonville and Tampa were coastal cities with moderate environmental matches based upon the Asian model; however, they receive very little ballast water discharge from possible donor regions. If, however, other potential vectors of mitten crab introduction, including seafood imports (Cohen and Carlton 1997), were to introduce this species to these areas, both port areas could seemingly be colonized successfully. Alternatively, these ports could be vulnerable if the founding population were genetically differentiated (e.g., directional selection) from that in the source and better adapted to prevailing conditions in these areas (e.g., McMahon 1996, Lee and Petersen 2002).

The approach used here has advantages over methods that only assess vector transport (e.g., Drake and Lodge 2004, Leung et al. 2004, MacIsaac et al. 2004). In order to estimate propagule supply via ballast water discharge, detailed knowledge is required of ballast practices of ships arriving in focal ports of interest (Verling et al. 2005). Vectors transmitting nonindigenous species and the pathways between sources and destinations are important for an understanding of the invasion process (Hilliard et al. 1997). This is consistent with a propagulepressure-based approach to risk assessment, which is supported by empirical evidence for an array of species (e.g., Rouget and Richardson 2003, Forsyth et al. 2004, Lockwood et al. 2005, Suarez et al. 2005).

\section{European vs. Asian model}

The Asian and European models, when combined with dispersal constraints, provided quite similar predicted ranges for mitten crabs in North America. Despite this, these models differed with respect to environmental suitability of coastal areas in the southeastern United States (Figs. 2 and 3). These differences are likely attributable to distribution differences in Europe and Asia. The crab is native to Asia, and thus its reported distribution there is relatively complete. Conversely, despite an invasion history in northern Europe that extends back as far as 1912 (Peters 1933), the species is still colonizing localities in southern Europe along the Atlantic coastline. Had colonization 
of southern Europe been more complete, inclusion of these sites into our European GARP model would almost certainly extend the projected distribution of mitten crabs farther south in the United States. If management decisions required selection of either of the Asian or European model predictions for the southeastern United States, we would err on the side of caution and opt for the former model since it had higher environmental matching for this region. The higher environmental match of western Canada in the European model is restricted to a very narrow strip along the coastline, rendering establishment of mitten crabs in this area very unlikely. Mitten crab distribution is also expanding in Great Britain and in coastal areas around the Baltic Sea. Northern range expansion in Europe would not influence projected distribution in the coterminous United States.

\section{North American mitten crab reports}

Our models allow us to compare expected distributions of mitten crabs with reported occurrences in the Chesapeake Bay, Great Lakes, lower Mississippi River, and San Francisco Bay (established population; Fig. 2A). The recent discovery of mitten crabs in Chesapeake Bay close to the port of Baltimore (G. M. Ruiz, unpublished manuscript) is consistent with our predictions that this region has the greatest relative risk of invasion (Tables 2 and 3). While suitability for survival in both models was predicted to be very high for all areas where crabs have been found in the lower Great Lakes (Figs. 2A and $3 \mathrm{~A}$ ), one mitten crab was found on a hydro intake screen in Lake Superior at Thunder Bay, Ontario (R. Eberhardt, personal communication). This location is proximal to an area with $7-11 \%$ environmental suitability according to the European model (Fig. 3A), but is outside the zone of suitability in the Asian model (Fig. 2A). Both Asian and European models suggest very low suitability for the Mississippi River; however these projections are likely artefacts of the manner in which the models were constructed. Both models included compound topographic index, which is in part related to river discharge. In addition, the European model also included river discharge directly (Table 1). Neither European nor Asian models incorporated rivers with flow rates as high as that of the Mississippi River, and thus this environment was assessed as unsuitable. Considering that live mitten crabs have been recorded from the lower Mississippi River and that adjacent areas are highly suitable environmentally (Figs. 2 and 3), we contend that the crabs may be capable of establishing in this watershed. San Francisco Bay-Oakland lies at a split point for environmental coverage in the Asian model. Some areas of this watershed were suitable for establishment whereas others were not, thus accounting for the high standard deviation (Tables 2 and 3 ) for this region. The European model predicted that this environment was unsuitable, although considering the limited southern distribution in Europe this prediction may not be reliable. Clearly, the fact that the crab is established in San Francisco Bay illustrates that suitable conditions exist in at least some areas. Our models identified this region as having a relatively low risk of invasion (Tables 2 and 3) due both to low propagule pressure and low environmental match. However, this outcome may be affected by several factors. Shipping patterns are changing, and past propagule supply by ships may have been greater, especially prior to ballast water treatment, which was implemented in the late 1990s. In addition, alternative introduction vectors could increase propagule pressure to the Bay, leading to a higher invasion risk. Genetic analysis of the San Francisco Bay population has suggested that it originated from Europe (Hanfling et al. 2002), while ballast water discharged into the Bay during the 1999-2003 period all originated from Asia. Thus, introduction via the live seafood trade may have been responsible for this population (Webb et al. 2003).

\section{Risk of secondary ballast water transport}

Our study does not include secondary transport of mitten crabs from San Francisco-Oakland to other North American ports. This problem appears to be inconsequential, considering that ballast water from San Francisco-Oakland is mainly released into Valdez Port, Alaska, which lies $4^{\circ} \mathrm{N}$ of environmentally suitable areas (Fig. 3). It seems that secondary spread presently poses a very small risk of larval transport, as the volume of ballast water released at locations with environmental suitability along the West Coast is very limited. Other potentially important secondary transport mechanisms such as hull fouling or pelagic larval dispersal from San Francisco Bay are outside the scope of this study.

\section{Future developments}

There remain several areas to consider in the application and further advancements of this predictive tool. First, these models do not address biotic interactions or the integrative ability of this species in recipient communities. If predators attack colonizing crabs, then establishment success could be further reduced. Second, shipping and ballast discharge patterns are highly dynamic, which obviously affects vector-based predictions. This is particularly true for ballast water treatment, which is now practiced on some ships and is rapidly evolving throughout the world. Also the frequency of ballast water exchange has increased dramatically in recent years (Miller et al. 2004). Because our analysis is based on the discharge volume of untreated ballast from 1999 to 2003, changes in ballast discharge volumes can affect the ability of our analyses to be representative of past or future patterns. Thus, such risk analyses address explicitly a specific time frame. Third, our current modeling of suitable conditions includes primarily water quality characteristics. Although this data set provides a conservative estimate of potential geographic range, other habitat characteristics (e.g., benthic substrate type, physical structure, 
vegetation cover, etc.) may provide improved resolution. These data exist for several bodies of water, but they are not yet readily available in aggregate or standardized fashion, constraining use in current applications.

\section{Conclusions}

Here we have developed an approach that uses a proxy for introduction effort combined with models that identify environmental suitability to predict vulnerability of North American coastal habitats to invasion by Chinese mitten crabs. Collectively, these models identify where Chinese mitten crabs are being introduced and where they are most likely to survive. Such information could be used for a focused management program, which for example could encourage mid-ocean ballast water exchange for ships arriving from risk areas in Europe and Asia to the ports of Norfolk, Baltimore, and Portland. Monitoring efforts could also focus on these high-risk ports to detect early signs of establishment similar to those developed for high-risk areas associated with commercial and recreational shipping in Australia and New Zealand (Hewitt and Martin 1996, Hewitt et al. 2004). As shipping patterns change, the risk level would require frequent reevaluation. Additionally, the inclusion of secondary transport from invaded sites such as San Francisco Bay, as well as an estimate of propagule pressure from illegal shipments of mitten crabs for the seafood trade, could be included.

\section{ACKNOWLEDGMENTS}

We are grateful to Mark Lewis at the Centre for Mathematical Biology at the University of Alberta for his help on the relative risk assessment. We also thank Debbie Rudnick and Yang Siliang for information pertaining to Chinese mitten crab distribution in Europe and Asia. Financial support from the National Science Foundation (to D. M. Lodge), the U.S. Coast Guard (to G. M. Ruiz), and NSERC CRO and Discovery grants and the Department of Fisheries and Oceans' Invasive Species Research Chair (to H. J. MacIsaac) is gratefully acknowledged.

\section{Literature Cited}

Anderson, R. P., D. Lew, and A. T. Peterson. 2003. Evaluating predictive models of species' distributions: criteria for selecting optimal models. Ecological Modelling 162:211-232.

Anger, K. 1991. Effects of temperature and salinity on the larval development of the Chinese mitten crab Eriocheir sinensis (Decapoda, Grapsidae). Marine Ecology Progress Series 72:103-110.

Arriaga, L., A. E. Castellanos, E. Moreno, and J. Alarcon. 2004. Potential ecological distribution of alien invasive species and risk assessment: a case study of buffel grass in arid regions of Mexico. Conservation Biology 18:1504-1514.

Blumenthal, D. 2005. Interrelated causes of plant invasion. Science 310:243-244.

Carlton, J. T. 1985. Transoceanic and interoceanic dispersal of coastal marine organisms: the biology of ballast water. Oceanographic and Marine Biological Annual Review 23: 313-371.

Choi, K.-H., W. Kimmerer, G. Smith, G. M. Ruiz, and K. Lion. 2005. Post-exchange zooplankton in ballast water of ships entering the San Francisco Estuary. Journal of Plankton Research 27:707-714.

Cleland, E. E., M. D. Smith, S. J. Andelman, C. Bowles, K. M. Carney, M. C. Horner-Devine, J. M. Drake, S. E. Emery,
J. M. Gramling, and D. B. Vandermast. 2004. Invasion in space and time: non-native species richness and relative abundance respond to interannual variation in productivity and diversity. Ecology Letters 7:947-957.

Cohen, A. N., and J. T. Carlton. 1997. Transoceanic transport mechanisms: introduction of the Chinese mitten crab, Eriocheir sinensis, to California. Pacific Sciences 51:1-11.

Colautti, R. I., I. A. Grigorovich, and H. J. MacIsaac. 2006. Propagule pressure: a null model for biological invasions. Biological Invasions 8:1023-1037.

Colautti, R. I., and H. J. MacIsaac. 2004. A neutral terminology to define 'invasive species.' Diversity and Distributions 10:135-141.

Davis, M. A., and M. Pelsor. 2001. Experimental support for a resource-based mechanistic model of invasibility. Ecology Letters 4:421-428.

de Lafontaine, Y. 2005. First record of the Chinese mitten crab (Eriocheir sinensis) in the St. Lawrence River, Canada. Journal of Great Lakes Research 31:367-370.

Drake, J. M., P. Baggenstos, and D. M. Lodge. 2005. Propagule pressure and persistence in experimental populations. Biology Letters 1:480-483.

Drake, J. M., and J. M. Bossenbroek. 2004. The potential distribution of zebra mussels in the United States. BioScience 54:931-941.

Drake, J. M., and D. M. Lodge. 2004. Global hotspots of biological invasions: evaluating options for ballast-water management. Proceedings of the Royal Society of London B 271:575-580.

Drake, J. M., and D. M. Lodge. 2006. Allee effects, propagule pressure and the probability of establishment: risk analysis for biological invasions. Biological Invasions 8:365-375.

Ferdinand-Martinez, M. A., and A. G. Carrera. 2003. Estatus de las poblaciones de cangrejos de rio exoticos, Procambarus clarkii, Pacifastacus leniusculus, y Eirocheir sinensis, en el Noreste de la peninsula Iberica. Pages 220-221 in L. Capdevila-Arguelles, B. Zilletti, and N. Perez Hidalgo, editors. Contribuciones al conocimiento de las Especies Exoticas Invasoras. Grupo Especies Invasoras Ed., G.E.I. Serie Tecnica, Leon, Spain.

Forsyth, D. M., R. P. Duncan, M. Bomford, and G. Moore. 2004. Climatic suitability, life-history traits, introduction effort, and establishment and spread of introduced mammals in Australia. Conservation Biology 18:557-569.

Ganeshaiah, K. N., N. Barve, N. Nath, K. Chandrashekara, M. Swamy, and R. U. Shaanker. 2003. Predicting the potential geographical distribution of the sugarcane woolly aphid using GARP and DIVA-GIS. Current Science 85:1526-1528.

Gollasch, S., et al. 2002. Life in ballast tanks. Pages 217-231 in E. Leppakoski, S. Gollasch, and S. Olenin, editors. Invasive aquatic species of Europe: distribution, impacts and management. Kluwer Academic, Dordrecht, The Netherlands.

Hanfling, B., G. R. Carvalho, and R. Brandl. 2002. mt-DNA sequences and possible invasion pathways of the Chinese mitten crab. Marine Ecology Progress Series 238:307-310.

Herborg, L.-M., S. P. Rushton, A. S. Clare, and M. G. Bentley. 2003. Spread of the Chinese mitten crab (Eriocheir sinensis, H. Milne Edwards) in continental Europe: analysis of a historical data set. Hydrobiologia 503:21-28.

Hewitt, C. L., and R. B. Martin. 1996. Port surveys for introduced marine species - background considerations and sampling protocols. Technical Report Number 4. Centre for Research on Introduced Marine Pests, CSIRO Division of Fisheries, Hobart, Tasmania, Australia.

Hewitt, C. L., J. Willing, A. Bauckham, A. M. Cassidy, C. M. S. Cox, L. Jones, and D. M. Wotton. 2004. New Zealand marine biosecurity: delivering outcomes in a fluid environment. New Zealand Journal of Marine and Freshwater Research 38:429-438.

Hilliard, R. W., J. A. Hutchins, and S. Raaymakers. 1997. Ballast water risk assessment, 12 Queensland ports, stage 4 report. Ecoports Monography Series 13:1-85. 
Iguchi, K., K. Matsuura, K. M. McNyset, A. T. Peterson, R. Scachetti-Pereira, K. A. Powers, D. A. Vieglais, E. O. Wiley, and T. Yodo. 2004. Predicting invasions of North American basses in Japan using native range data and a genetic algorithm. Transactions of the American Fisheries Society 133:845-854.

Jeschke, J. M., and D. L. Strayer. 2005. Invasion success of vertebrates in Europe and North America. Proceedings of the National Academy of Sciences (USA) 102:7198-7202.

Johnson, C. J., and M. P. Gillingham. 2005. An evaluation of mapped species distribution models used for conservation planning. Environmental Conservation 32:117-128.

Kolar, C. S., and D. M. Lodge. 2002. Ecological predictions and risk assessment for alien fishes in North America. Science 298:1233-1236.

Lee, C. E., and C. H. Petersen. 2002. Genotype-by-environment interaction for salinity tolerance in the freshwater-invading copepod Eurytemora affinis. Physiological and Biochemical Zoology 75:335-344.

Leung, B., J. M. Drake, and D. M. Lodge. 2004. Predicting invasion: propagule pressure and the gravity of Allee effects. Ecology 85:1651-1660.

Levine, J. M., P. B. Adler, and S. G. Yelenik. 2004. A metaanalysis of biotic resistance to exotic plant invasions. Ecology Letters 7:975-989.

Levine, J. M., and C. M. D'Antonio. 1999. Elton revisited: a review of evidence linking diversity and invasibility. Oikos 87:15-26.

Lockwood, J. L., P. Cassey, and T. Blackburn. 2005. The role of propagule pressure in explaining species invasions. Trends in Ecology and Evolution 20:223-228.

Lodge, D. M. 1993. Biological invasions: lessons for ecology. Trends in Ecology and Evolution 8:133-137.

Lonsdale, W. M. 1999. Global patterns of plant invasions and the concept of invasibility. Ecology 80:1522-1536.

MacIsaac, H. J., J. V. M. Borbely, J. R. Muirhead, and P. A. Graniero. 2004. Backcasting and forecasting biological invasions of inland lakes. Ecological Applications 14:773783.

McMahon, R. F. 1996. The physiological ecology of the zebra mussel Dreissena polymorpha, in North America and Europe. American Zoologist 36:339-363.

McNyset, K. M. 2005. Use of ecological niche modelling to predict distributions of freshwater fish species in Kansas. Ecology of Freshwater Fish 14:243-255.

Miller, A. W., G. M. Ruiz, and K. Lion. 2004. Status and trends of ballast water management in the United States. Second biennial report. National Ballast Information Clearinghouse, Edgewater, Maryland, USA.

Nepszy, S. J., and J. H. Leach. 1973. First records of the Chinese mitten crab, Eriocheir sinensis, (Crustacea: Brachyura) from North America. Journal of the Fisheries Research Board of Canada 30:1909-1910.

Peters, N. 1933. Lebenskundlicher Teil. Pages 59-155 in N. Peters, A. Panning, and W. Schnakenbeck, editors. Die chinesische Wollhandkrabbe (Eriocheir sinensis H.MilneEdwards) in Deutschland. Zoologischer Anzeiger, Akademische Verlagsgesellschaft M.B.H., Leipzig.

Peterson, A. T. 2003. Predicting the geography of species' invasions via ecological niche modeling. Quarterly Review of Biology 78:419-433.

Peterson, A. T., and K. P. Cohoon. 1999. Sensitivity of distributional prediction algorithms to geographic data completeness. Ecological Modelling 117:159-164.

Peterson, A. T., and D. A. Vieglais. 2001. Predicting species invasions using ecological niche modeling: new approaches from bioinformatics attack a pressing problem. BioScience 51:363-371.

Raxworthy, C. J., E. Martinez-Meyer, N. Horning, R. A. Nusselbaum, G. E. Schneider, M. A. Ortega-Huerta, and A. T. Peterson. 2003. Predicting distributions of known and unknown reptile species in Madagascar. Nature 426:837-841.

Ricciardi, A., and S. K. Atkinson. 2004. Distinctiveness magnifies the impact of biological invaders in aquatic ecosystems. Ecology Letters 7:781-784.

Romanuk, T. N., and J. Kolasa. 2005. Resource limitation, biodiversity, and competitive effects interact to determine the invasibility of rock pool microcosms. Biological Invasions 7: 711-722.

Rouget, M., and D. M. Richardson. 2003. Inferring process from pattern in plant invasions: a semimechanistic model incorporating propagule pressure and environmental factors. American Naturalist 162:713-724.

Roura-Pascual, N., A. V. Suarez, C. Gomez, P. Pons, Y. Touyama, A. L. Wild, and A. T. Peterson. 2004. Geographical potential of Argentine ants (Linepithema humile Mayr) in the face of global climate change. Proceedings of the Royal Society of London B 271:2527-2534.

Rudnick, D. A., K. Hieb, K. F. Grimmer, and V. H. Resh. 2003. Patterns and processes of biological invasion: the Chinese mitten crab in San Francisco Bay. Basic and Applied Ecology 4:249-262.

Ruesink, J. L. 2005. Global analysis of factors affecting the outcome of freshwater fish introductions. Conservation Biology 19:1883-1893.

Silfverberg, H. 1999. A provisional list of Finnish Crustacea. Memoranda Societatis pro Fauna et Flora Fennica 75:15-37.

Stockwell, D., and D. Peters. 1999. The GARP modelling system: problems and solutions to automated spatial prediction. International Journal of Geographical Information Science 13:143-158.

Suarez, A. V., D. A. Holway, and S. Ward. 2005. The role of opportunity in the unintentional introduction of nonnative ants. Proceedings of the National Academy of Sciences (USA) 102:17032-17035.

Underwood, E. C., R. Klinger, and P. E. Moore. 2004. Predicting patterns of non-native plant invasions in Yosemite National Park, California, USA. Diversity and Distributions 10:447-459.

Valovirta, I., and R. Eronen. 2000. The first Chinese mitten crab (Eriocheir sinensis) of the interior country, in Rantasalmi. Memoranda Societatis pro Fauna et Flora Fennica 76: 23-25.

Verling, E., G. M. Ruiz, L. D. Smith, A. Galil, A. W. Miller, and K. R. Murphy. 2005. Supply-side invasion ecology: characterizing propagule pressure in coastal ecosystems. Proceedings of the Royal Society of London B 272:12491256.

Walker, S., J. B. Wilson, and W. G. Lee. 2005. Does fluctuating resource availability increase invasibility? Evidence from a New Zealand short tussock grassland. Biological Invasions 7: 195-211.

Webb, K., D. Bergendorf, and E. Williams. 2003. National management plan for the genus Eriocheir (mitten crabs). U.S. Fish and Wildlife Service, Stockton Fish and Wildlife Office, Stockton, California, USA.

Wonham, M. J., J. T. Carlton, G. M. Ruiz, and L. D. Smith. 2000. Fish and ships: relating dispersal frequency to success in biological invasions. Marine Biology 136:1111-1121.

Wonham, M. J., M. A. Lewis, and H. J. MacIsaac. 2005. Minimizing invasion risk by reducing propagule pressure: application to ballast-water exchange. Frontiers in Ecology and the Environment 9:473-478.

\section{APPENDIX}

A table showing the source of environmental coverages used in the predictions (Ecological Archives A017-028-A1). 